\title{
Wildlife in Zaïre
}

\section{Jacques Verschuren}

Zaire is one of the foremost African countries in the field of wildlife conservation, with large areas of wild country still almost untouched, a magnificent range of wildlife, large well managed national parks, and the will and intention to conserve and extend these, as President Mobutu Sese Seko has made clear. This year conservationists from all over the world will be able to see a little of how this vast country is conserving its wildlife when they meet there for the IUCN General Assembly. In this article the former Director General of Zaire's Institut National pour la Conservation de la Nature, who has worked there as a biologist since 1948, surveys the main wildlife areas. A second article, in the next Oryx, will describe the status of the major mammals.

A bird's eye view of the wildlife situation in Zaïre has a particular relevance in 1975, for in September the International Union for Conservation of Nature (IUCN) is holding its 12th General Assembly at Kinshasa, capital of the Republic. Even more important, Zaïre itself is in many ways a leader among African nations and its conservation policies stand as an example to other African countries.

As a biologist in the national parks since 1948 and Director General of the Institut National pour la Conservation de la Nature (INCN) from 1969 to 1974, I have been able to visit recently, and off the beaten track, almost the whole of Zaïre, including of course all the reserves, using the most diverse methods of travel, from light aircraft to old-fashioned foot safaris lasting several weeks and accompanied by African helpers to carry the equipment. One point needs emphasis at the start: Zaïre is, without any doubt, in the forefront of African conservation in its management of its seven strict nature reserves, which are admirably supervised; but the situation is not so satisfactory in the rest of the country, where hunting is not adequately controlled.

\section{The President's Plans}

The head of state, President Mobutu Sese Seko, in a speech in 1972, expressed officially both the wish and the will to set aside between 12 and 15 per cent of the country's total land area in nature reserves. We hope that this wish will be soon fulfilled. At present only two and a half per cent of Zaïre is included in effectively protected reserves.

This rapid survey of the wildlife situation in Zaïre will be divided into two parts: first a review of the principal natural and hunting regions of the country followed by a survey of the typical mammals. (Part 2 will appear in the next Oryx.) It will hardly touch the extensive literature, especially the work of Schouteden. Most publications before 1960, when Zaïre became independent, are largely out of date. Some authors, however, notably Curry-Lindahl, Grzimek, Harroy and Schaller have made interesting contributions since that date. The mine of information possessed by the Zaïrois Conservators of the reserves is so far unpublished. 

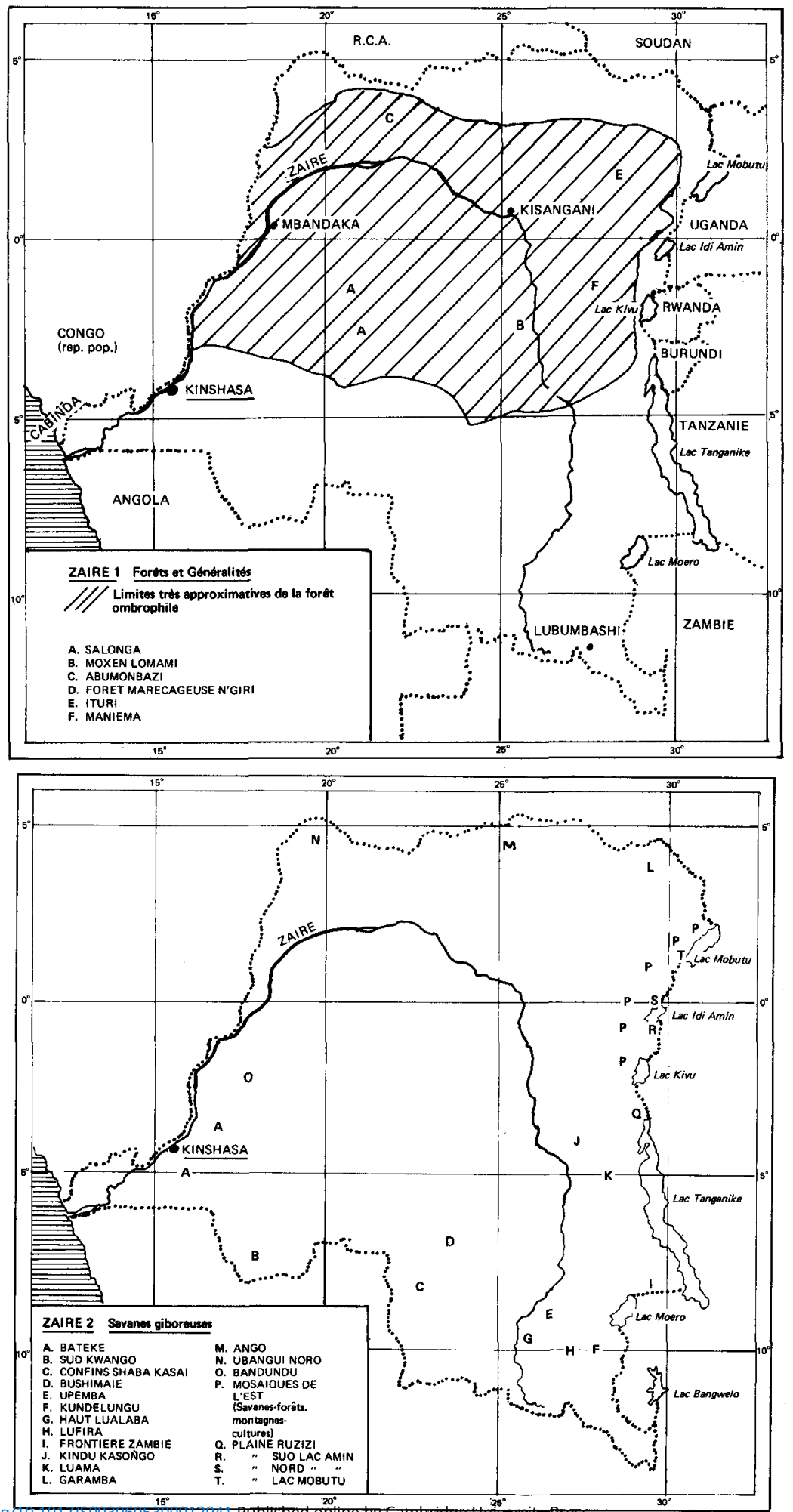

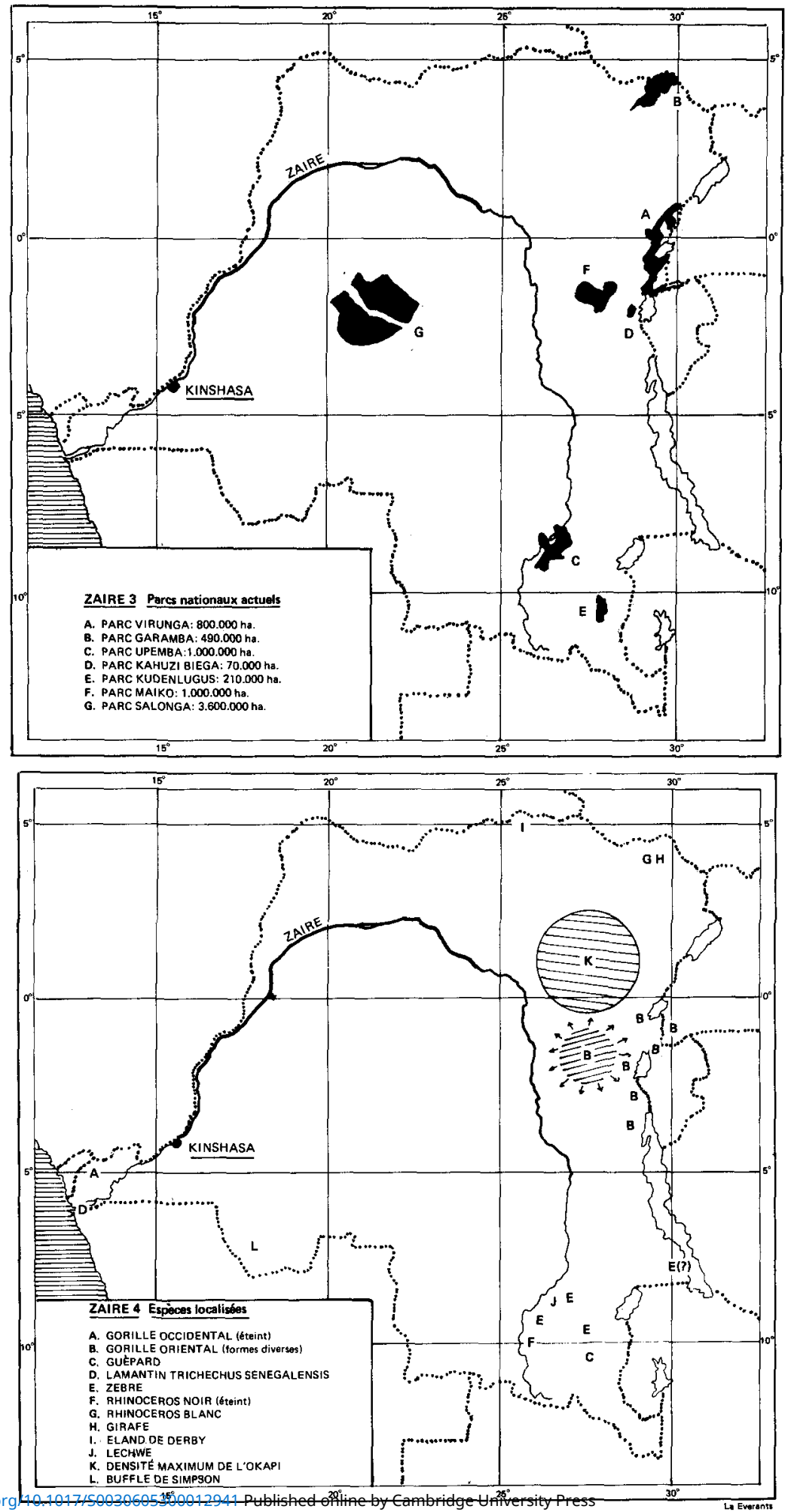


\section{Main Wildlife Areas}

Zaïre is the second largest country in Africa, covering 2,400,000 sq. km. (roughly $1,000,000$ sq. $\mathrm{m}$., or 80 times the size of Belgium). The altitude ranges between sea level and the summit of Ruwenzori, which at $5119 \mathrm{~m}$. is the third highest point on the continent. The country straddles the Equator, between latitudes $5^{\circ} \mathrm{N}$ and $15^{\circ} \mathrm{S}$. Nearly all African biotopes are represented, the exceptions being desert, semi-desert, coral reefs and marine islands, and this extraordinary range of habitats explains the incredible variety of the fauna. A large part of the country, towards the west and centre, is relatively flat with extremely broken hilly country in the south-east and the mainly volcanic east. The dry season, which lasts longest in the extreme south - where it is seven months - is not a limiting factor for the fauna. Rainfall, seldom lower than $400 \mathrm{~mm}$. except in unusual years, can in some places be as high as $3000 \mathrm{~mm}$. Except in a few localities the human population, which is between 20 and 22 million, is not particularly dense.

Approximately half the total land surface is covered by rain forest - see map 1. Recent aerial surveys have shown that forest destruction has been far less serious than one would have believed possible, and confined to a narrow strip along the roads. The forest is crossed, especially in the 'equatorial basin', by a network of easily navigable rivers, which of course provide easy access for hunters; along these rivers the larger animals have been almost completely exterminated. For a long time now it has been unusual to see a single mammal during the 8-10 days it takes to navigate the Zaïre river between Kinshasa and Kisangani, and the same is true of most of the tributaries. The eastern watercourses (Maniema area, Ituri) are not so easy to negotiate, being interrupted by falls, and here there has been less wildlife destruction.

Although the forest is increasingly broken up by roads, there are still huge blocks between the main waterways and the roads almost untouched and only sparsely inhabited by humans, even, in places, only half-explored. A considerable fauna survives in these sections, although of course, the population density of forest-dwelling animals is never great. They are well protected because hunters rarely penetrate farther than $20-25 \mathrm{~km}$. into the forest from the roads. All the human population is found along these roads, except for certain pygmy or pygmoid groups which, as they use 'traditional' hunting methods, do not do irreparable damage.

These large forests are the domain par excellence of abundant elephants and buffaloes, innumerable small antelopes, and, in places, bongos and okapis; sitatungas are extremely numerous in the swampy forest. The wild animals often seem to seek out the secondary forest. The zones bordering the roads and rivers are evidently subjected to intensive poaching, in some cases by hunters coming from distant parts and acting as victuallers to the big towns.

The best intact forest regions (see map 1) include, to mention just a few, the Salonga block*, which must extend unbroken for at least $80,000 \mathrm{sq} . \mathrm{km}$., and of which $36,000 \mathrm{sq}$. $\mathrm{km}$. has been set up as a nature reserve, and the immense, almost unexplored forest (B), that stretches between the Lualaba and Lomami rivers. North of the Zaïre river there is a beautiful intact block, the Abumonbazi forest to the north of Lisala (C). The forest swamps around Mbandaka

* The localities on the maps are approximate 

Bushimaie at Kasai (Jobaert) is said to be less badly damaged than was thought, but this has to be confirmed (C and D).

The very big Shaba region, with a low human population except near the mining towns, presents three different aspects. The high plateaus rising to nearly $2000 \mathrm{~m}$., with a salubrious climate and a grand panorama over the slopes and the Lofoi Falls. Where nature reserves have been created on these high plateaus (Upemba, Kundelungus, $E$ and F), wildlife is still relatively abundant; where there is no protection (Kibara and Marungus) it is almost totally exterminated. This is the area for zebra, roan and eland. The largest part of the Shaba, at a rather lower altitude, is covered by an endless forest of thin Brachystegia where the wildlife is very scattered. Despite the small number of actual inhabitants this area is heavily poached by people from the mining centres. The huge papyrus marshes (Lualuba and Lufira, $G$ and $H$ ), are the home of numerous elephants, sitatunga and, in places, also lechwe. A lot of game coming in from Zambia is still to be found along the frontier between Lakes Mweru and Tanganyika (I).

The fauna of the savanna-forests towards Kindu-Kasongo-Kibombo (J) is little known, but abundant tracks suggest large numbers of elephants.

The Luama valley (K), despite its inaccessibility (or thanks to it), has remained a relative paradise for wildlife. Although buffaloes have been practically exterminated, elephants are numerous, and pukus occur in thousands.

But without any doubt the most interesting area in Zaïre, outside the national parks, is the vast savanna north of the forest (and of the Equator), which stretches for hundreds of kilometres along the frontiers of the Central African Republic (CAR) and the Sudan to Uganda. In the east is the Garamba National Park (L) with white rhinos and giraffes; in the west the future Ango Park (M) with enormous tusked elephants and giant eland. Sparsely populated, this is the only part of the country where game can be seen freely all along the tracks. Along the Bomu, however, there is a great deal of poaching, thanks to the proximity of the CAR.

To the north of the Ubangui $(\mathrm{N})$, a region I have not visited, animals survive in fair numbers. Between Mushie and Bandundu $(\mathrm{O})$, not far from Kinshasa, the vast, heavily wooded savannas are still intact, with no lack of game. Unfortunately, now that the Bateke plateau has been practically hunted out, the Kinshasa professional meat hunters have designs on this area. Only the urgent gazetting of the whole region as a reserve can save these beautiful savannas and their forest galleries.

The high plateaus in the east and north-east, dominated by lofty mountains and isolated from the low plains, present a completely different picture. Essentially these are the regions of Kivu and Ituri. On the western slopes, which are generally not very steep, the rain forest extends up to an altitude of 1200-1500 metres. On most of the mountain sides, especially between 1200 and $2200 \mathrm{~m}$., the natural vegetation has been almost totally destroyed, wildlife is non-existent, and there is a dense human population - for example the Djomba area near Rutshuru, the Bashi sector near Bukavu, and the regions of the Wanande and Walendus. Fortunately the most interesting areas were protected in time, fifty years ago, and constitute the remarkable Parc National des Virungas, formerly the Albert National Park. The high peaks outside the parks are relatively intact, such as the Itombwe, but nevertheless suffer from serious erosion due to overgrazing. Nature has given the alpine zones 


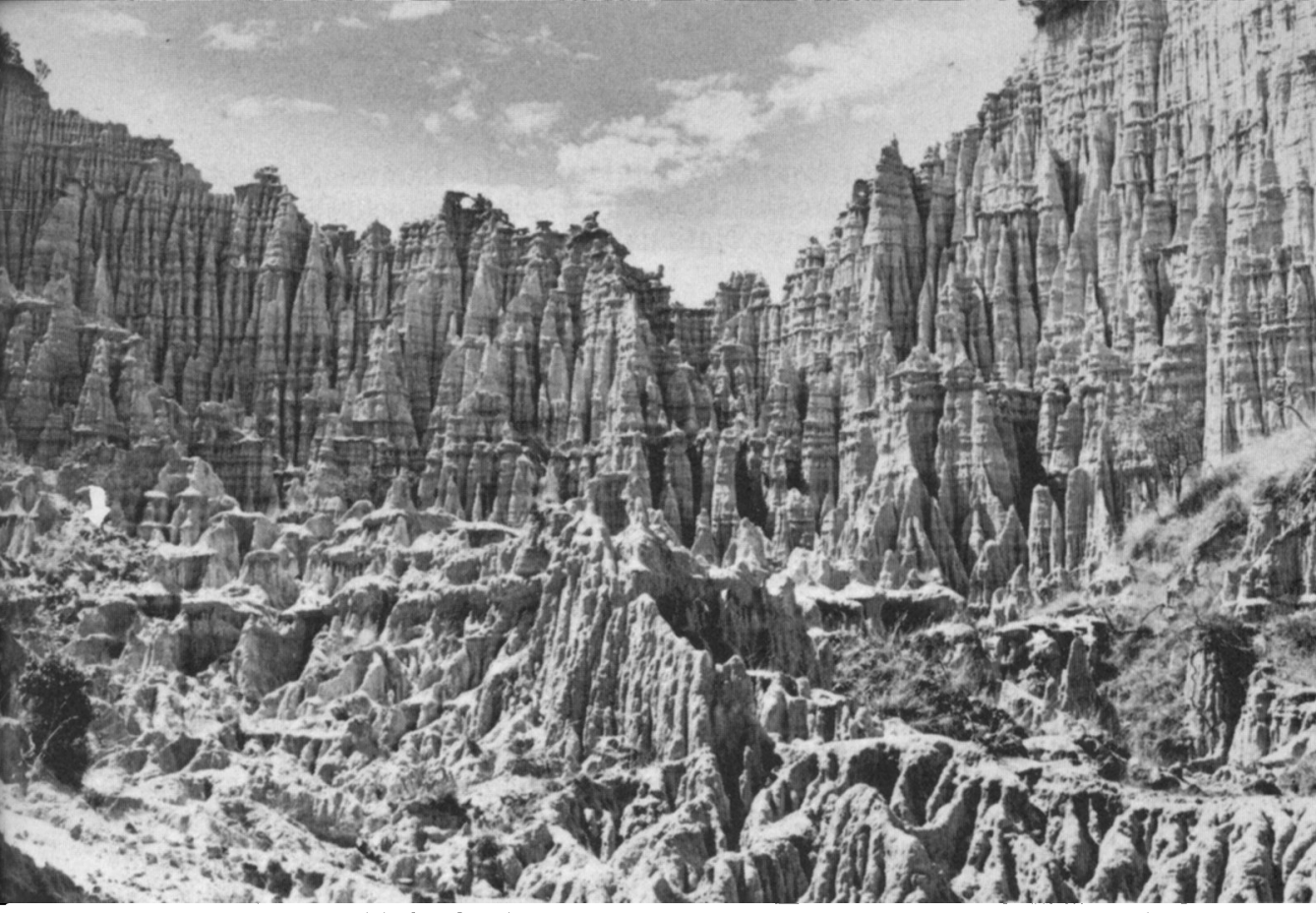

THE 'LUNAR' CLIFFS OF SINDA

Jacques Verschuren

their own defence, but in places domestic livestock ranges as high as $3750 \mathrm{~m}$.

In Zaïre all the extraordinary volcanoes, both active and extinct, and also the Ruwenzori, are completely protected. However, it is near the lakes in the very dry low plains completely surrounded by mountains, that the highest animal densities occur, comparable and sometimes superior to those of East Africa. Four of these plains are particularly noteworthy: Ruzizi, a Borassus plain to the north of Lake Tanganyika $(R)$, where the once abundant fauna has been almost entirely exterminated by hunting and other activities, although some hippos and crocodiles must survive in the rivers; the plain south of Lake Idi Amin (formerly Edward), in the heart of the Virunga National Park, with thousands of antelopes, lions, and an exceptional abundance of hippos (S); the plain to the north of Lake Idi Amin (T), with its wonderful site at Ishango, the true source of the White Nile, where the fauna, decimated in part in the 1914-18 war and much more in the 1960-64 rebellion, is obviously less abundant now. This plain is separated from the plains of Lake Mobutu (formerly Albert) by a strip of rain forest, which is of unique interest and unequalled scientific value since it is practically the only place in Africa where a transect of the vegetation between the rain forest of the plain and the alpine zone exists intact; and finally the plains south of Lake Mobutu where, until about 1958, wildlife was abundant and comparable with that of the Virunga National Park. But poaching on a frightful scale has sealed its death warrant, and the local hunters are reduced to hunting rats in order to feed themselves. The surviving lions kill livestock, which in turn is fairly scarce. In spite of all this a nucleus of wild animals - elephants, hippos, antelopes - does subsist there (though far less numerous than on the Uganda bank of the Semliki) and could re-establish itself. This plain is intersected by the extraordinary 'lunar' 
cliffs of Sinda, and not far away is Mount Hoyo with its unusual grottoes, only partially explored, which are the refuge of okapis. The inclusion of this plain and of Mt Hoyo in the Virunga National Park is at present in hand: it is the priority of priorities in Zaïre.

Near Lake Kivu there is no longer any game, but the lake's tourist attractions are self-evident.

In short, Zaïre constitutes a veritable mosaic of regions, some with abundant wildlife and others completely empty, quite apart from the large central forest bloc, which for several decades will remain a last refuge.

\section{Commercial Hunters}

What are the main causes of the reduction in wildlife in Zaire outside the national parks? The destruction of the biotope does not play an important part except in a few regions; the increase in human population must be checked, but only locally for the country is vast. The answer is, in fact, uncontrolled hunting. 'Traditional' hunting by local populations has no serious effects; it has always existed and can even be encouraged, so long as only 'authentic' weapons are used - bows, arrows, pygmy nets. Unfortunately the pygmies in some areas now use nylon nets, and, like everywhere else in Africa, wire snares cause horrible destruction. Fortunately the possession of powerful guns is not allowed, although since the 1964 rebellion there are far too many illegal firearms. The real culprits in the destruction are the 'gangs' coming out from the towns who ravage everything. This is true especially of Kinshasa, and other cities, where monkeys and small antelopes are the favourite victims. Near the Shaba mining towns the sellers of the meat are often foreigners, and one must not forget the poaching raids from neighbouring countries - CAR, Republic of Congo, Sudan, Uganda, Rwanda, Tanzania, Zambia, Angola frequently by non-Africans. Sport-hunting by non-Africans is hardly developed, despite some attempts, but plans exist, and, correctly managed, it could be valuable.

At the time of writing, January 1975, the lack of an effective Wildlife Department is serious, (though the situation may change soon). It has been estimated that 80 per cent of the people know nothing about the legislation, and hunt without any control. Most of it, dating from before 1960 , is obsolete, but efforts are being made to update it. The administration, which on the one hand often seems indifferent or even culpable, on the other hand sometimes shows considerable interest in ending the poaching, especially at higher levels, for wildlife is increasingly being regarded by those in authority as a valuable heritage.

The army, as in many other countries, is not completely innocent. Sometimes it has helped significantly in the fight against poaching; at others, especially in remote regions and in operational sectors (frontiers), it is responsible for serious destruction, being of course well armed. Recently, however, there has been progress on this front and heavy penalties have been imposed on military poachers. The responsibility of some Europeans, Hindus and other nonZaïrois, for hunting and above all for illegal exports, is equally evident. As in other parts of Africa, the pastoral peoples, Tutsis, Bahemas, and others respect wildlife and do not poach, and the same is true of most fishermen, who are numerous in some areas.

The greatest danger in the immediate future lies in the incredible increase 
in the world ivory trade. Many elephants have already fallen victim to this, and ivory is often exported illegally by foreigners, to the detriment of the State's finances.

\section{Inside the Parks}

In Zaïre's seven national parks (map 3), on which a number of documents will be published, the situation is generally very good, and sometimes outstandingly so; it is to be hoped that funds will not be lacking to implement plans for the future. On the President's instructions, plans for new national parks have been drawn up, and will shortly be gazetted, we hope with adequate financial backing. Zairre must remain among those countries in the forefront of conservation, and not allow herself to fall behind. With very few exceptions now the management of parks and reserves, at all levels, is entirely in the hands of nationals, and their enthusiasm augurs well for the future. Management of the parks makes use of the most up-to-date techniques, including aeroplanes and radio communication. Zaïre is probably alone in being able to claim that each park guard is equipped with a powerful rifle which may be used against offenders. So far there have been no abuses. This arming of the guards is essential, especially when it is remembered that thirty guards gave their lives in the service of nature conservation during the difficult years, often for lack of adequate arms.

Nor is scientific research in the national parks being neglected. In addition to a station for ringing palearctic migrants at Lulimbi in the Parc National des Virungas, which is one of the most important in Africa-30,000 birds have been ringed in three years - studies are being carried out on the structure of hippo populations and their impact on the environment, as the basis for eventual management techniques which should obviously be put into practice with great caution. The giant forest hog Hylochoerus meinertzhageni, an almost unknown animal, is also the object of detailed study. In other reserves the INCN, which is responsible direct to the President (the best solution for a conservation organisation), is also concerned with the Epulu and Gangala na Bodio stations (okapis and elephants). Environmental problems are also being studied.

\section{Three Conferences}

'The Stockholm conference on the human environment did not discuss population. The Bucharest conference on population did not discuss environment, and recently the Rome conference on world food problems did not discuss either environment or population. This would make sense if the human race did not live in the biosphere, or if ecological laws could be suspended by United Nations vote. ...

'The leaders of the nations of the world have now come together in three major international conferences where they had the opportunity to confront the realities of the biosphere, and to address themselves to finding answers to the question of how humanity can continue to survive in a world worth living in. Because of international rivalries and in the interest of short-term political gains, they have three times refused to address themselves to the real issues. It is difficult to be optimistic about such concerns as the conservation of wildlife and natural areas when our leaders show such little real concern for the future of mankind.' $R$. $F$. Dasmann in the IUCN 'Bulletin'. 